bases para formar escultores nacionales en un país donde aún no existía una Academia de Bellas Artes". En la Escuela Nacional de Artes y oficios se formaron Raúl Pro, Romano Espinoza Cáceda, Artemio Ocaña, Luis Agurto, Víctor Tessey Dini, Francisco Beteta, Pedro José Morante, Julio Hidalgo, Lorenzo Bermúdez, Juan Icochea Herrera y Francisco Caso Uria, entre los más destacados. Si a esta lista unimos los escultores que saldrán de la Escuela de Bellas Artes, fundada en 1918, tendremos un sorprendente número de artistas dedicados a la labor escultórica en Lima.

Un aporte indiscutible de Leonardini son los datos sobre el mosaista Amadeo Mantellato, quien sobre la base de los dibujos de Giovanni Buffa, realizó las Alegorías sobre la cultura italiana en la entrada del Museo Italiano, inauguradas en 1921 y La entrega del bastón de mariscal a Cáceres, sobre la base del óleo de Luis Ugarte. También el acucioso trabajo de revisión de diarios y revistas de Lima ha hecho posible dar con las obras de Umberto Feltrin: la maqueta de La yunta de bueyes, de cuyo modelo Ismael Pozo elaboró su escultura El trabajo, hoy en el Paseo de la República, si no la han cambiado de sitio.

En fin, la lista de artistas italianos con obra en el Perú es larga y ocuparía mucho tiempo hablar de cada uno de ellos; tampoco quisiera quitarles a los futuros lectores la sorpresa de descubrirlos. El trabajo de Nanda Leonardini es un aporte a la cultura de nuestro país con las influencias y ejemplos que hemos recibido de otras partes del mundo que la han enriquecido.

\title{
Sobre Las buenas intenciones
}

Castrillón Vizcarra, Carlos Alfonso

\section{LAS BUENAS INTENCIONES}

Lima: Editorial Universitaria de la Universidad Ricardo Palma. 2018.

371 págs. 84 ils, ISBN:978-612-4419-01-0

Bajo el título Las buenas intenciones, el crítico de arte y académico Alfonso Castrillón (Lima, 1935), presenta una selección de artículos sobre diversos temas culturales que han sido publicados en revistas, libros, catálogos y periódicos. El texto más antiguo se remonta a 1978 y el más reciente a 2015, lo que representa un espacio de treinta y siete años, en los que podemos notar cuáles son los lineamientos que han permanecido a lo largo de la trayectoria del autor y que hacen parte fundamental de su acercamiento a la cultura.

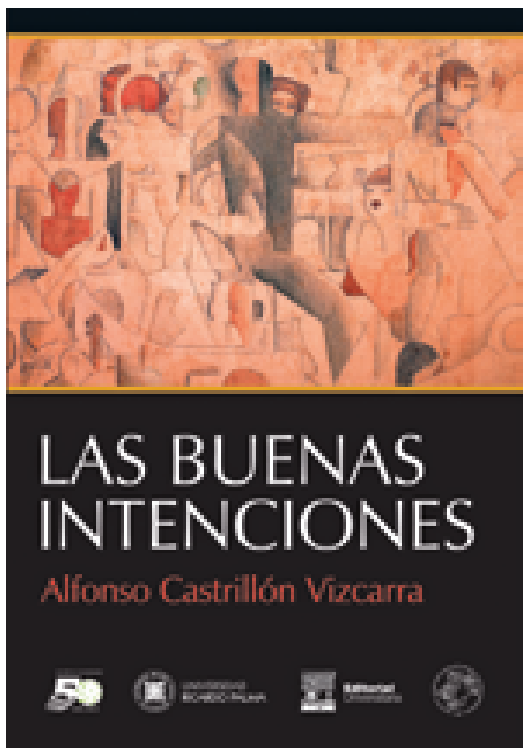


En el primer capítulo de este libro, aparece un análisis sobre la historia y las implicancias de la crítica de arte en el Perú. El lector descubre desde las primeras páginas lo que ha significado la crítica de arte en nuestro país y quiénes han sido las primeras figuras en ejercer esta disciplina: Juan Tassara, Federico Larrañaga, Pareja de Mijares, Clemente Palma y José García Calderón, son algunas de las personalidades citadas. La caracterización de estos intelectuales como "burgueses", que encaraban la crítica no como "especialistas" sino como "amateurs" (p. 29), da paso a un debate, que se perfila a través de las páginas, sobre las condiciones que se requieren para ser un crítico de arte. Por medio de Teófilo Castillo, pintor peruano del siglo XIX y principios del XX que escribía en la revista Actualidades, se nos muestra la importancia de que un crítico no sea solo un simple aficionado, sino un profesional que además de tener un amplio conocimiento del medio artístico, maneje conceptos que le permitan emitir opiniones con sustento.

Si bien la crítica de arte pertenece al ámbito de lo subjetivo, puesto que lo que se busca es valorar una obra y en ello influye el gusto, el que la ejerce tiene que aspirar a una cierta objetividad. Esto lo explicaba ya Margit Rowell en un artículo de 1968 titulado La crisis de la crítica de arte:

El juicio crítico se desarrolla en varias etapas. Primero es subjetivo, y debe alcanzar luego una cierta objetividad. Eso solo puede ocurrir después de un análisis técnico y formal de la obra y del estudio de su significancia y de su necesidad histórica. Solo entonces se puede emitir un juicio crítico ${ }^{1}$ (p. 299).

El crítico de arte tiene que desapasionar sus opiniones, y para ejercer su rol, necesita no solo tener una sensibilidad artística, sino también conocimientos sólidos en todo lo relacionado al arte, conocer desde las dimensiones técnicas hasta sus evoluciones a través del tiempo. Sus opiniones pueden tener así una importancia clave dentro de la sociedad: por medio de ellas se promueve el surgimiento de artistas, la creación de escuelas, el encauzamiento de un movimiento artístico, la aparición de galerías y exposiciones; como también contribuyen a generar debates y despertar el pensamiento crítico.

En otros seis artículos de este primer capítulo del libro, se abordan los aportes de José Carlos Mariátegui al campo de la crítica del arte. Así, vemos a este pensador debatiendo con Teófilo Castillo; inquiriendo desde Italia sobre si convenía o no en los años veinte hacerle un homenaje a Dante a través de la cinematografía; enviando informaciones a Lima sobre el futurismo; creando la revista Amauta y dándoles importancia en su publicación a las ilustraciones, algo novedoso en esos tiempos, como bien destaca Castrillón.

A través del ejemplo de Emilio Adolfo Westphalen, que defendía las obras de arte plástica de César Moro y de José María Eguren; o de Juan Ríos Rey y de Raúl María Pereira, que criticaban al indigenismo por supuestamente haber privilegiado, según ellos, el tema sobre la forma; el autor del libro examina en este capítulo a los críticos de arte improvisados que de alguna manera no advierten que, así como para ser artista se requiere de un entendimiento técnico del oficio, los que teorizan sobre arte tienen que aspirar también a una profesionalización de su trabajo, y no pueden basar sus juicios únicamente en intuiciones.

Tomas de posición como estas, aparecen a lo largo de las páginas, y el lector descubre que el autor no duda en adentrarse en debates espinosos y opinar con claridad. En el segundo capítulo del libro, por ejemplo, se aborda el tema tan controversial que fue el del Premio Nacional de Cultura otorgado al retablista ayacuchano Joaquín López Antay en 1975. Castrillón no solo fue testigo de esta controversia, sino también actor de este

1 Cita original: "Le jugement critique se fait en plusieurs temps. D’abord subjectif, il doit atteindre une certaine objectivité. Ceci ne peut se faire qu'après une analyse technique et formelle de l'œuvre et l'étude de sa signification et de sa nécessité historique. Alors on peut énoncer un jugement critique" (traducción propia). 
suceso, puesto que integró el jurado que decidió otorgarle el premio a López Antay, quien competía con candidatos como los pintores Núñez Ureta y Quíspez Asín.

Este premio generó una gran polarización entre los artistas e intelectuales peruanos de la época. Mientras que algunos, como el pintor Fernando de Szyszlo, consideraban que el retablo no podía ser valorado como un objeto de arte al poder ser reproducido en serie, otros, como el escultor Víctor Delfín, defendieron el reconocimiento de un retablista con estilo propio. La Asociación Profesional de Artistas Plásticos (Aspap) emitió un comunicado el 1 de enero de 1976 en el que expresaba "su radical discrepancia respecto del fallo", y esto por considerar que con ello se establecía que la artesanía tenía en el proceso cultural del país "una significación mayor que la pintura o la música" (Gargurevich, 2016, s. p.). Para la Asociación fue llamativo que se eligiera además una "expresión artesanal que -según ellos- no lograba superar su primigenia inspiración colonial” (Ibídem).

A pesar de estas críticas, el premio representó un momento clave en la escena artística peruana. El fallo, logró romper con los límites entre el denominado "arte popular" y el "arte culto", o-como lo llama el autor del libro- el "arte informado"; y, además, recompensó por primera vez una expresión artística proveniente de la sierra del Perú. El campesino andino pasa así de ser un simple objeto de contemplación, como lo había sido en las pinturas indigenistas, a ser reconocido también como actor de los procesos artísticos. Para el autor del libro, "lo que hacía el maestro ayacuchano era arte, como expresión de una individualidad que interpretaba al mundo andino mestizo y que merecía estar en el mismo nivel de las creaciones informadas" (p. 193).

En el segundo capítulo del libro, el autor nos introduce en la vida y trabajos de algunos de los artistas más emblemáticos del siglo XX en el Perú, lo que representa una introducción interesante para los neófitos y un trabajo de reflexión para los estudiosos del tema. De Jorge Eduardo Eielson aparece una entrevista que le hizo el autor en el 2005, y en la que descubrimos más sobre las lecturas, la afición por la música y las amistades de este destacado artista peruano. Nos enteramos así de anécdotas singulares, como aquella en la que el profesor José María Arguedas le llamó la atención a su alumno Eielson y lo acusó de plagio luego de que este le presentara un trabajo sobre los trágicos griegos tan bien escrito que, Arguedas, no creía que su alumno pudiera haber sido el autor.

De Tilsa Tsuchiya nos describe la evolución de su pintura, y vemos cómo la estética de la artista fue influenciada por el súbito interés que su obra concitó en los años del Gobierno de Velasco Alvarado; mientras que la pintura de Alberto Quintanilla es presentada como una obra con reminiscencias del arte popular cusqueño, con alusiones al mundo precolombino y a los cuentos populares. A Gerardo Chávez, otro pintor surrealista, el autor le dedica dos artículos, en los que vemos cómo este artista se aventuró siempre en hacer nuevas propuestas, por lo que Castrillón considera que frente a su obra solo cabe "el asombro perpetuo". Otros artistas mencionados en esta sección son Wassily Kandinsky y Víctor Escalante, pasando por Josué Sánchez, José Antonio Núñez y Johanna Hamann. El autor presenta la obra de esta última a través de un poema, lo que nos demuestra que el teórico de arte nunca está muy lejos él mismo de la creación artística.

No podemos dejar de mencionar el artículo dedicado al crítico de arte Juan Acha, que cierra este capítulo y que se presenta como una forma de homenaje a este destacado intelectual peruano. De Acha nos revela, a través del encuentro que tuvo con él, que era una persona que irradiaba "una gran simpatía" y que era "generoso, dispuesto a ayudar a los jóvenes artistas que se le acercaban” (p. 304). Castrillón lo sabe de primera mano porque en este artículo nos cuenta cómo Acha lo guio al mundo de la crítica de arte y fue una suerte de mentor para él. 
En el tercer capítulo, así como lo hizo en los capítulos anteriores, los textos tienen un estilo sin subterfugios: se elogian publicaciones como La rebelión de los lápices, una obra de Ramón Mujica Pinilla en donde se analiza la caricatura del siglo XIX en el Perú; y el libro E.P.S. Huayco de Gustavo Buntinx, en donde, como su título lo indica, se aborda el tema de este colectivo artístico de los años ochenta. Los juicios van acompañados a veces de toques de humor, como cuando el autor comenta con ironía los análisis imaginativos de Gustavo Buntinx acerca de una serigrafía de María Luy: "Le aseguro, lector, que la nariz de esa señora, que así expone el trasero, no tiene nada de fálica y las 'fantasías de castración reparada' no son, seguramente, aplicables a la artista” (p. 325).

En otros momentos, el tono se endurece, sobre todo cuando se trata de criticar la podredumbre cultural que acecha nuestro país. El artículo dedicado a comentar un libro de la Escuela Nacional Superior Autónoma de Bellas Artes del Perú, que se publicó en el año 2009, se vuelve el ejemplo que refleja la falta de minuciosidad y de investigación que puede haber en una obra financiada con presupuestos del Estado.

En el último capítulo de esta publicación, titulada "Museos", el tono anticonformista se refleja aún con mayor fuerza. La frase que abre este capítulo revela una lucha, que ya se nos anunciaba desde las primeras páginas del libro: "Permítanme comenzar con una afirmación drástica", nos advierte el autor, "el Estado peruano nunca ha tenido una seria preocupación por el patrimonio y los museos de la Nación” (p. 355). Este reclamo es recurrente en la obra, y encontramos siempre una protesta a la informalidad que reina en el Perú, que puede reflejarse desde la mala edición de un manuscrito, como fue el caso del mencionado libro de la Escuela de Bellas Artes, hasta la puesta en escena de una obra de teatro en el Cementerio Presbítero Maestro que tuvo como resultado la destrucción de un monumento fúnebre en el 2006.

“¿Qué idea pueden hacerse los niños peruanos de su pasado y qué perspectivas imaginan para el futuro si visitan un museo oscuro y destartalado, reino de polillas y roedores y donde las momias se exhiben irrespetuosamente?", se pregunta Castrillón al analizar el estado de los museos en el Perú (p. 340), especialmente de los museos de provincia, que se caracterizan por la falta de personal capacitado, de inventarios y de una política estatal que busque fomentar la investigación o la conservación de los objetos.

En otro momento, el autor critica a los alcaldes que, en lugares públicos, buscan colocar esculturas que no comulgan con el entorno, o que buscan restaurar obras sin tener conocimiento de sus técnicas. Una anécdota sobre Luis Castañeda Lossio es reveladora sobre esto: el alcalde habría ordenado, cuando estaba en función, lijar los bronces de la Fuente China, "hasta ponerlos dorados" (p. 366), sin respetar la pátina del tiempo que les otorga todo su valor. Los presidentes y primeras damas tampoco se salvan de las recriminaciones, y en una clara referencia a lo que hacían Alejandro Toledo y Eliane Karp (aunque no son citados directamente), se les acusa de buscar popularidad a través de grandes exposiciones, estrenadas con bombos y platillos, cuando los museos nacionales están abandonados y no existe una política cultural que busque preservarlos y revalorizarlos.

Detrás de estas críticas, hay un espíritu de lucha que trasciende, un descontento que busca generar cambio, despertar conciencia para salir de la mediocridad. Estamos frente a una economía tercermundista, nos dice Castrillón en un artículo que describe cómo los proyectores del Museo Metropolitano de Lima se apagaron a las pocas semanas de uso por falta de presupuesto; pero esto no necesariamente implica una limitación: somos un país tercermundista, pero nuestro retraso nos ha librado también "de las tentaciones liberales de alquilar nuestras colecciones a los países desarrollados" (p. 351). No se necesita tampoco incurrir en grandes gastos para potenciar un museo; existen alternativas, según el autor, 
como "las maquetas, los maniquíes, los dioramas, pero, sobre todo, los objetos reales" (p. 362 ), que simplemente hay que poner en valor.

El libro termina entonces con un grito de protesta, reclamando más espacio para los especialistas, para los investigadores, para que se puedan crear proyectos coherentes, para tener museos que exhiban el patrimonio cultural de forma ordenada, atractiva y didáctica para el público, y para que se instalen esculturas en los espacios públicos que sean armoniosas con el entorno. Tal vez así se pueda revertir la siguiente opinión que Teófilo Castillo ya emitía en el siglo XIX, que el libro recoge y que parece aún vigente en el Perú: "Hay que confesar -dice Castillo- que en ninguna parte como aquí la ignorancia tiene mayores audacias" (p. 42).

Las buenas intenciones es una publicación de lectura indispensable para todos aquellos que quieran conocer más sobre crítica de arte, sobre museología, sobre la estética de algunos de los artistas peruanos más importantes del siglo XX. El libro también puede interesar a los que quieran conocer más sobre los planteamientos de Alfonso Castrillón acerca de la gestión cultural, aportes valiosos que deberían ser tomados en cuenta por todos lo que se ocupan del arte en nuestro país.

No es el propósito del libro, pero hay un aspecto autobiográfico que se desliza a través de las páginas y que da luces también sobre el trabajo de Castrillón como investigador y crítico de arte. Este es uno de los puntos por los cuales el libro va más allá de la pura teoría, y cautiva no solo por la tecnicidad de los juicios expresados, que revelan un amplio conocimiento del autor, sino también por las anécdotas que nos son narradas, como la del premio a López Antay; y por la aparición de personas con las cuales el autor tuvo contacto directo y que ya han fallecido, como Juan Acha y Carlos Quíspez Asín. Este libro trata de arte desde un punto de vista formal, pero también puede ser considerado como el testimonio de toda una época y de los personajes que marcaron la esfera artística peruana durante la segunda mitad del siglo XX.

\section{Bibliografía}

Castrillón, A. Las Buenas Intenciones. Lima: Editorial Universitaria, Instituto de Investigaciones Artísticas y Museológicas de la Universidad Ricardo Palma, 2018.

Gargurevich, Juan. "El día que López Antay derrotó a los cultos de Lima". Recuperado de: https://tiojuan.wordpress.com/2017/08/15/eldia-que-lopez-antay-derroto-a-los-cultos-de-li$\mathrm{ma} /, 2016$.
Rowell, M. "La Crise de la Critique d'Art". En The MIT Press, julio, 1968. 